\title{
O processo de gestão documental e da informação arquivística no ambiente universitário
}

\author{
Wilmara Rodrigues Calderon \\ Bacharel em biblioteconomia pela Universidade Estadual de Londrina. \\ Mestre em ciência da comunicação pela Escola de Comunicação e \\ Artes da Universidade de São Paulo. Docente do Departamento de \\ Ciência Informação da Universidade Estadual de Londrina/PR. \\ E-mail: calderon@uel.br \\ Julce Mary Cornelsen \\ Bacharel em biblioteconomia e documentação pela Fundação Sociologia \\ e Política de São Paulo. Mestre em ciência da comunicação pela Escola de \\ Comunicação e Artes da Universidade de São Paulo. Docente do Departamento \\ de Ciência da Informação da Universidade Estadual de Londrina/PR. \\ E-mail: julce@dilk.com.br \\ Neiva Pavezi \\ Bacharel em arquivologia pela Universidade de Santa Maria/RGS. \\ E-mail: pavezi@uel.br
}

\section{Maria Aparecida Lopes}

Bacharel em biblioteconomia pela Universidade Estadual de Londrina. Mestre em ciência da informação pela Unesp/Marília. Docente do Departamento de Ciência da Informação da Universidade Estadual de Londrina/PR.

E-mail: maplopes@sercomtel.com.br

\section{Resumo}

Os estudos desenvolvidos no país acerca do processo de gestão documental/informacional demonstram a disposição teórica de diferentes especialistas em melhor compreender a questäo documental. O projeto que está sendo desenvolvido por professores e alunos do curso de arquivologia da Universidade Estadual de Londrina tem a pretensão de contribuir de algum modo com essa discussão. Para isso, propõe estudar diterentes aspectos que envolvem a gestão documental/ informacional em instituições e organizações no âmbito público. Para o desenvolvimento da pesquisa, elegeu-se a entrevista estruturada e a observação direta como técnicas para a coleta de dados visando à elaboração de um diagnóstico de arquivo. O desenvolvimento de um estudo dessa natureza traz experiências importantes para a equipe que busca o suporte da literatura especializada e faz reflexões a respeito da aplicabilidade dos conhecimentos obtidos em uma realidade concreta.

Palavras-chave

Gestão documental e informacional; Informação arquivística; Diagnóstico em arquivos.

The management process of documents and archival information in the universities

\footnotetext{
Abstract

The studies carried out in the country on the documentary/ informational management process demonstrate the theoretical enthusiasm from different experts for better understanding the documentary issue. The project that has been developed by teachers and students from the Archivology Course at the State University of Londrina intends to contribute somehow to this discussion. It is proposed to study different aspects which involve the documentary/informational management in public institutions and organizations. As for the development of research, the structured interview and direct observation were chosen as procedures for the data gathering, aiming at the elaboration of a record survey. The development of such a study brings important experiences for the staff that seeks the specialized literature support and reflects upon the applicability of the knowledge obtained in a concrete reality.

Key words

Documentary and informational management;

Processing of documents; Records survey.
}

\section{INTRODUÇÃO}

A necessidade de registrar as informações decorrentes da experiência humana, em sua imensa diversidade, tem produzido um grande número de registros que a testemunham e indicam os caminhos trilhados, possibilitando o seu conhecimento e reavaliação. É preciso não repetir os mesmos erros e atingir novos patamares no sentido de encontrar alternativas/soluções para problemas que se apresentam como novos ou transmudados.

Esses registros constituem-se no que é designado como documentos, ou seja, um conjunto de informações registradas em um suporte. Para que esses cumpram sua função social, administrativa, técnica, jurídica, cultural, entre outras, é necessário que estejam organizados, sejam preservados e acessíveis.

A história da evolução dos arquivos, segundo Bautier (apud Cruz Mundet,1994) e Romero Tallafigo (1994) é dividida em quatro períodos, a saber: a época dos arquivos de palácio, que corresponde em termos gerais à Antigüidade; a época dos cartórios, abarcando os séculos XII a XVI; a época dos arquivos como arsenal de autoridade, que se estende por todo o Antigo Regime, desde o século XVI ao século XIX; e a época dos arquivos como laboratório da história, desde o início do século XIX até meados do século XX.

Vale destacar que a Bíblia registra no livro de Esdras $(6,1)$, escrito entre 456 e 444 antes de Cristo, que "o rei Dario deu ordem, e uma busca se fez nos arquivos reais da Babilônia, onde se guardavam os documentos" (Bíblia...,1998).

No Egito, na Grécia e em Roma, na Antigüidade, já se respeitava a procedência do documento que sustenta a formação dos chamados "fundos arquivísticos", um dos princípios fundamentais da arquivística, até os dias de hoje.

Os arquivos do início da Idade Moderna trouxeram em si a influência daqueles que se formaram durante o declínio das civilizações desenvolvidas na Antigüidade e na Idade Média, sendo dotados de uma visão exclusivista de guarda dos documentos, enquanto instrumentos da administração, para uso restrito do governo. Essa concepção dos arquivos prevaleceu até o final do século XVIII, como relata Côrtes (1996, p.17). 
A partir do século $\mathrm{XX}$, os arquivos abriram-se à administração, aos cidadãos e aos pesquisadores de diferentes áreas e, à frente desses, fez-se necessária a presença de profissionais preparados a responder às expectativas e necessidades dos usuários que buscam informações para a elaboração de seus trabalhos. Nos arquivos, o conteúdo informacional dos documentos diz respeito às atividades dos respectivos produtores, mas, como em qualquer outra instituição, a preocupação com a organização e disponibilização das informações é a tônica que prevalece.

No que diz respeito à administração da informação, evidencia-se uma "insuficiência" dos ambientes informacionais. Há pouca informação acessível sobre funcionários, clientes e até mesmo sobre os próprios produtos das organizações. Nesse sentido, Davenport (2000, p.16) refere-se aos prejuízos decorrentes do processo decisório baseado em informação incorreta:

Obviamente, um pesquisador não pode ler a mente de um administrador para descobrir que tipo de informação possui, quando a obteve, de onde a recebeu e como é utilizada no momento da tomada de decisão. Mas ninguém pode negar que decisões baseadas em dados inúteis têm custado bilhões de dólares em produtos encalhados, em aquisições que não acrescentam lucratividade ao conjunto, em processos redefinidos que não funcionam, em investimentos em instalações ou equipamentos que não produzem.

No que diz respeito à produção de conhecimento na área de ciência da informação, constata-se que as rápidas transformações sociais decorrentes do desenvolvimento científico e tecnológico, ocorridas nas últimas décadas, deram ensejo à criação do Programa Sociedade da Informação, em diversos países, com o objetivo de elaborar políticas de inserção em um mundo globalizado com conexões e tecnologias intensas. Para tanto, especialistas em diversas áreas do conhecimento juntaram-se para elaborar propostas iniciais em termos de educação, saúde, cultura, trabalho, transportes, governo eletrônico, política de desenvolvimento científico e tecnológico, entre outras, elaborando diretrizes nessas áreas que estão consolidadas no chamado Livro Verde. No Brasil, esse Programa* tem por finalidade

lançar os alicerces de um projeto estratégico, de amplitude nacional para integrar e coordenar o desenvolvimento e a utilização de serviços avançados

\footnotetext{
* Foi desenvolvido a partir de um estudo do Conselho Nacional de Ciência e Tecnologia e instituído pelo decreto presidencial n. 3294, de 15 de dezembro de 1999, e é coordenado pelo Ministério da Ciência e Tecnologia.
}

de computação, comunicação e informação, e de suas aplicações na sociedade, de forma a alavancar a pesquisa e a educação, bem como assegurar que a economia brasileira tenha condições de competir no mercado mundial (Programa, 2000, p.1).

No bojo dessas transformações, está a universidade como instituição de vanguarda na produção de conhecimento, com a responsabilidade de formar profissionais capacitados a atender às novas demandas provenientes desse contexto.

As implicações desse quadro contemporâneo para todas as áreas de conhecimento, principalmente para aquelas que têm a informação como matéria-prima de seu trabalho, causam impacto, uma vez que seus paradigmas sofrem profundas e significativas alterações, com alta taxa de rotatividade, em períodos de tempo muito curtos.

A investigação está diretamente relacionada ao progresso de qualquer área de conhecimento, como observam Rousseau e Couture (1998, p. 277), ao afirmarem que "não há verdadeira formação, sem que esta se baseie na investigação". Investigações sobre o corpo de conhecimento de uma ciência, sobre o mercado de trabalho e sobre o próprio profissional tornam-se assim imprescindíveis na busca de uma melhoria da qualidade da formação do profissional, bem como da capacitação do docente pesquisador.

Nesse sentido, merece ser lembrada a primeira Reunião Brasileira de Ensino de Arquivologia (Rebrarq), realizada em 1995, que estabeleceu, entre outras, as seguintes recomendações: a ampliação, no âmbito dos currículos de graduação e de pós-graduação, de abordagens quanto à gestão da informação arquivística no ambiente empresarial; e que "a formação de arquivistas esteja referida às demandas sociais e científicas do moderno profissional da informação" (Jardim; Fonseca, 1999, p. 198).

Pelo exposto, este estudo, de caráter exploratório-descritivo, visa a contribuir para o avanço da área arquivística, à medida que tem por objetivo analisar a gestão documental/informacional de instituições da região de Londrina - Paraná.

\section{ARQUIVOS E INFORMAÇÃO ARQUIVÍSTICA}

Considerar a importância dos arquivos nas organizações passa, necessariamente, pela reflexão e compreensão do que significa arquivos e informação. Nesse sentido, resgatam-se as definições contidas em manuais clássicos da área, nos quais arquivo é o "conjunto de documentos que, independentemente da natureza ou do suporte, são 
reunidos por acumulação ao longo das atividades de pessoas físicas ou jurídicas, púbicas ou privadas" (Camargo e Bellotto, 1996, p.5).

Em uma perspectiva contemporânea, a qual valoriza o conteúdo informacional registrado nos documentos, Lopes $(2000$, p. 33) apresenta como conceito de arquivo os

acervos compostos por informações orgânicas originais, contidas em documentos registrados em suporte convencional ou em suportes que permitam a gravação eletrônica, mensurável pela sua ordem binária (bits); produzidos ou recebidos por pessoa física ou jurídica, decorrentes do desenvolvimento de suas atividades, sejam elas de caráter administrativo, técnico, artístico ou científico, independentemente de suas idades e valores intrínsecos.

Rousseau e Couture (1998, p.63-65) afirmam que qualquer organismo, independentemente de tamanho, missão ou setor de atividade, para existir, funcionar e se desenvolver, necessita de informação. Nesse sentido, todos os membros do organismo têm necessidade de informação para desempenhar suas funções. Para tanto,

arranjam a informação necessária tanto no exterior como no interior do organismo. Essa informação pode ser verbal ou registrada num suporte como o papel, a fita magnética, o vídeo, o disco óptico ou o microfilme. Pode ser orgânica, isto é, elaborada, enviada ou recebida no âmbito da sua missão, ou não-orgânicas, isto é, produzida fora do âmbito desta. A produção de informações orgânicas registradas dá origem aos arquivos do organismo.

Nesse sentido, vale lembrar que o conceito de informação arquivística vem se consolidando entre os arquivistas canadenses, preconizando maior relação entre a arquivologia e a ciência da informação (Fonseca, 1998).

Concorda-se com Couture (1996, p.8), que, em uma época na qual o progresso tecnológico nos projetou na era da informação, "o arquivista, como todos os que trabalham com a informação, deve atravessar a parede do formato - o documento - para ir à direção do conteúdo, a informação".

A informação,

quando adequadamente assimilada, produz conhecimento, modifica o estoque mental de informações no indivíduo e traz benefícios ao seu desenvolvimento e ao desenvolvimento da sociedade em que vive (Lustosa, 2002, p. 129).
Da mesma forma, Furtado (1982, p.28) aponta que a informação

traduz causa e efeito, estratégia e produto; eficiência na organização de recursos e eficácia nos resultados, em seus aspectos de qualidade e êxito, em relação aos anseios e necessidades do ambiente.

Acredita-se que a maioria das instituições, atualmente, ultrapassou a obsessão tecnológica para encarar algo mais complexo, que é a preocupação que se deve ter com a informação produzida no âmbito interno e externo afetando os processos e os produtos das organizações.

Diante dessas concepções de arquivo e de informação, depreende-se que a informação não tem sido considerada apenas objeto privilegiado da arquivística, aparecendo na literatura clássica da área como conseqüência do documento de arquivo, que, por sua vez, é visto como um elemento do arquivo. Assim sendo, Heredia Herrera alerta: "Importa muito que não percamos de vista a tríplice dimensão do objeto da arquivologia e sua ordem: arquivos-documentos de arquivo-informação" (apud Fonseca, 1998, p.33).

A literatura clássica da arquivística reflete o interesse no valor secundário dos documentos, por isso têm sido enfatizados os arquivos históricos. Em contrapartida, surge a arquivística integrada com a proposta de tratar a informação desde o nascimento até o seu destino final.

A arquivística integrada é definida como a "única com capacidade de assegurar a unidade e a continuidade das intervenções no quadro de uma política de organização dos arquivos" (Rousseau ; Couture apud Lopes, 2000, p.133).

Essa nova proposta tem como diretrizes a eleição da informação registrada como objeto de pesquisa e trabalho, a busca de parcerias com áreas afins, a ênfase na pesquisa teórica e aplicada e o estímulo à formação de profissionais qualificados para planejar soluções para os problemas arquivísticos.

A informação orgânica e registrada é por natureza uma informação arquivística que apresenta como características:

1. a natureza das informações arquivísticas é específica; trata-se de informações registradas em suporte definido, acumuladas por um indivíduo ou por um organismo que é, ao mesmo tempo, produtor e receptor;

2. a primeira característica da informação arquivística é a sua natureza orgânica, isto é, sua relação umbilical com o produtor; 
3. a segunda característica é a sua originalidade, logo, a sua unicidade;

4. a terceira característica é a sua capacidade de ser avaliada em termos de idade e de utilização;

5. a primeira particularidade da informação arquivística é a natureza limitada dos seus suportes - convencionais ou eletrônicos;

6. a segunda particularidade refere-se à noção de acumulação das informações - produzidas ou recebidas - por um indivíduo ou um organismo, desde que sejam informações capazes de ter significação;

7. a terceira particularidade refere-se às atividades geradoras que podem ser administrativas, técnicas ou científicas;

8. a quarta particularidade refere-se ao fato de a informação arquivística ser a primeira forma tomada por uma informação registrada, quando da sua criação (Revista Archives, 1988 apud Lopes, 2000, p.103).

Conforme assinala Lopes (2000),

a natureza das informações arquivísticas é específica; trata-se de informações registradas em suporte definido, acumuladas por um indivíduo ou por um organismo que é, ao mesmo tempo, produtor e receptor.

De acordo com essa visão, a informação arquivística apresenta como características: 1) a sua natureza orgânica, isto é, a sua relação umbilical com o produtor; 2) a sua originalidade, logo, a sua unicidade; 3 ) a sua capacidade de ser avaliada em termos de idade e de utilização. Dentre as particularidades da informação arquivística, ainda são assinaladas: a) a natureza limitada dos seus suportes - convencionais ou eletrônicos; b) aquelas referentes à noção de acumulação das informações - produzidas ou recebidas - por um indivíduo ou um organismo, desde que sejam informações capazes de ter significação; c) aquelas que se referem às atividades geradoras que podem ser administrativas, técnicas ou científicas; d) o fato de ser a informação arquivística a primeira forma tomada por uma informação registrada, quando da sua criação (Revista Archives, 1988 apud Lopes, 2000, p.103).

Ainda é preciso não esquecer que, em arquivo, mesmo na esfera dos correntes, o documento raramente vale como peça solta. É sempre parte do todo a ele relacionado seja a sua série, grupo ou seção - que deve ser tomada. A conceituação é válida para os arquivos administrativos, sejam os do campo privado ou público, e é aplicável às suas três idades. Dessa forma:

Para que se entenda tal conceituação é fundamental ter de perto o princípio de respect des fonds, no qual está baseada toda a moderna arquivística. Além disso, estamos tratando de fundo e não de coleções: só faz sentido, portanto, a ligação documento-gestão administrativa aí configurada (Belloto, 1991, p.24).

Não havendo gestão, planejamento e operação da informação arquivística, de acordo com Lopes (2000, p. 217), não se pode:

$\checkmark$ planejar e desenvolver atividades, considerando o capital informacional prévio;

$\checkmark$ tomar decisões político-administrativas ou pessoais baseadas em dados acumulados;

$\checkmark$ atender às necessidades legais e técnicas;

$\checkmark$ evitar a repetição completa ou parcial de atividades, economizando recursos materiais e humanos;

$\checkmark$ recuperar a história.

Como a informação arquivística é imaterial, sua gestão passa necessariamente pela gestão de documentos de conteúdos informacionais estratégicos ou não.

\section{A GESTÃO DOCUMENTAL E INFORMACIONAL EM INSTITUIÇÕES PÚBLICAS}

Constata-se nessas instituições o dilema de grandes massas documentais acumuladas, sobretudo em suporte papel, guardadas sem tratamento adequado. Nelas estão depositadas frações significativas dos registros da história das organizações e não é raro, também, existirem valores técnicos, científicos, jurídicos, probatórios e outros, misturados a uma quantidade enorme de documentos sem nenhum valor.

As informações arquivísticas, em qualquer instituição pública ou privada, são de caráter contábil/financeira, pessoal e administrativa, que podem ser encontradas em diferentes espécies documentais. Portanto, ao se propor um trabalho de gestão documental e informacional, é necessário, antes de qualquer iniciativa, conhecer bem a instituição/organização. Sem o conhecimento histórico sociológico das mesmas, torna-se difícil entender o ciclo da informação/documento. 
O pré-diagnóstico e o diagnóstico devem ser o ponto de partida para os projetos de organização de documentos, subsidiando a proposta de modelos de classificação, avaliação e descrição apropriadas, visando a um destino final eficiente e eficaz.

O levantamento geral dos dados sobre as atividades, fluxo informacional, estruturas e funções retratam a concepção que a instituição/organização tem sobre a importância e valor da informação.

O tratamento da informação, com a finalidade de recuperação e uso, supõe conhecimento e aplicação conjunta de teoria, metodologia e prática. É necessária a atenção especial no diagnóstico, na constituição, na manutenção, ou seja, na gestão de arquivos. Todas as tentativas fora dessa teoria redundarão em pseudo-arquivos onde tudo se acumula e nada se localiza.

Para Lopes (1997, p.110), os documentos devem receber

tratamento global que resulte no aumento das possibilidades do uso da informação registrada para tomada de decisões nos arquivos correntes e nas suas extensões, os intermediários.

O termo gestão está relacionado à administração, ao ato de gerenciar. Isso significa que é preciso ir além do ato de registro da informação em um suporte, é preciso também que se tenha um planejamento de tal forma, que, mesmo com uma quantidade exacerbada de documentos gerados diante das ferramentas tecnológicas disponíveis nos dias atuais, seja possível localizar e utilizar a informação no tempo exato e necessário para uma tomada de decisão.

A gestão de documentos originou-se na impossibilidade de se lidar, de acordo com "moldes tradicionais", com as massas cada vez maiores de documentos produzidos pelas administrações públicas americanas e canadenses. Assim, a partir das soluções apontadas por comissões governamentais nomeadas para a reforma administrativa dos Estados Unidos e do Canadá, no final da década de 40 do século XX, foram estabelecidos princípios de racionalidade administrativa, a partir da intervenção nas etapas do ciclo documental, a saber: produção, utilização, conservação e destinação de documentos (Fonseca, 1998, p.38). Destacam-se, então, as principais atividades e funções dessas etapas:

$\checkmark$ produção: concepção e gestão de formulários, preparação e gestão de correspondências, gestão de informes e diretrizes, fomento de sistemas de gestão da informação e aplicação de tecnologias modernas a esses processos; $\checkmark$ utilização e conservação: criação e melhoramento dos sistemas de arquivos e de recuperação de dados, gestão de correio e telecomunicações, seleção e uso de equipamento reprográfico, análise de sistemas, produção e manutenção de programas de documentos vitais e uso de automação e reprografia nestes processos;

$\checkmark$ destinação: a identificação e descrição das séries documentais, estabelecimento de programas de avaliação e destinação de documentos, arquivamento intermediário, eliminação e recolhimento dos documentos de valor permanente às instituições arquivísticas.

No Brasil, a gestão de documentos se institucionalizou com a aprovação da Lei 8.159 de 8 de janeiro de 1991, que dispõe sobre a política nacional de arquivos públicos e privados. A mencionada lei, em seu artigo $3^{\circ}$, define gestão documental como sendo

o conjunto de procedimentos e operações técnicas referentes à sua produção, tramitação, uso, avaliação e arquivamento em fase corrente e intermediária, visando a sua eliminação ou recolhimento para guarda permanente (Brasil, 1991).

A Unesco define gestão de documentos como uma parte do processo administrativo relacionado com a aplicação de princípios de economia e eficácia tanto na iniciação, acompanhamento e uso dos documentos, quanto em sua eliminação (Heredia Herrera, 1993, p.177) (tradução nossa).

Na prática, a gestão de documentos pode representar o desenvolvimento das seguintes tarefas:

$\checkmark$ estudo da tipologia documental, seu valor, vigência, classe e qualidade de sua informação;

$\checkmark$ normalização de documentos para simplificação de etapas administrativas, inclusive as repetitivas, e de formulários para remessa e estatísticas (investigação, empréstimos);

$\checkmark$ informatização de processos de tramitação documental;

$\checkmark$ coordenação e colaboração entre organismos produtores e arquivo;

$\checkmark$ regulamentação das transferências que possibilitam a reclamação dos produtores em caso de não se fazerem as remessas nos prazos estabelecidos;

$\checkmark$ estudo da classificação em cada caso, materializada na adoção de um quadro, resultado de um organograma estabelecido; 
$\checkmark$ eleição da ordenação mais adequada, segundo as séries, nas organizações e em áreas de uma informação mais efetiva e rápida;

$\checkmark$ estudo dos descartes e suas listas, com o conseqüente estabelecimento de acordos para evitar a remessa de séries descartáveis aos arquivos centrais;

$\checkmark$ incorporação de fundos e manutenção da informação atualizada;

$\checkmark$ preparação de informações mediante a solicitação para o estudo de qualquer tema ou preparar qualquer projeto;

$\checkmark$ elaboração de índices e de tesauros;

$\checkmark$ planejamento para informatização (Heredia Herrera, 1993, p.177) (tradução nossa).

Essas tarefas tiveram um impacto no perfil das instituições arquivísticas, principalmente na administração pública,

na medida em que não mais se limitavam a receber, preservar e dar acesso aos documentos produzidos pelo estado, mas, antes, assumem a liderança na execução das políticas públicas relacionadas à gestão de documentos (Fonseca, 1998, p.38).

\section{TEORIA E PRÁTICA DA GESTÃO DOCUMENTAL/INFORMACIONAL: UM CAMINHO A PERCORRER}

A pesquisa "Gestão documental e informacional: tratamento, recuperação e disseminação da informação" está sendo desenvolvida por professores e alunos do Departamento de Ciência da Informação, no Curso de Arquivologia da Universidade Estadual de Londrina, e se propõe estudar os diferentes aspectos que envolvem a gestão documental e informacional em instituições e organizações no âmbito público.

A realidade organizacional a ser estudada foi a Universidade Estadual de Londrina (UEL). A equipe da pesquisa optou em aproximar o objeto de seu estudo às necessidades dessa instituição, que vem discutindo a necessidade da gestão documental e informacional e a possível implantação de seu sistema de arquivos - o Sauel.

Definido o local para a realização da pesquisa, o passo seguinte foi tomar conhecimento de diferentes propostas para conhecer a realidade arquivística a ser trabalhada. Lopes (1997, p.43) traz à tona uma discussão sobre o procedimento do profissional arquivista para o conhecimento "ideal" da realidade em que se pretende intervir, ou seja,

as atividades, fluxo informacional, estruturas, funções e as questões referentes aos acervos constroem o objeto da pesquisa ao retratar a situação arquivística da organização, na forma de um diagnóstico.

Para a realização do diagnóstico, além do aporte teórico, é importante contar com metodologias adequadas e instrumentos próprios, que coletem informações precisas em cada etapa do processo, para subsidiar a proposição de ações de intervenção. Nesse sentido, Lopes (1997) corrobora que o profissional arquivista deve se apropriar dos métodos da sociologia e da história, considerando que o arquivista trabalha com fragmentos da vida social e da história da organização.

É preciso ter critérios que ajudem a selecionar o método mais apropriado à realidade pretendida, reconhecer o melhor momento para sua aplicação, enfim, é preciso estudar os diferentes métodos a ponto de sentir-se seguro para fazer a escolha, pois "o talento do pesquisador consiste em adequar os métodos às necessidades dos objetos" (Lopes, 1997, p.45).

Diante de tais constatações, elegeu-se a entrevista estruturada e a observação direta como técnicas para a coleta dos dados. Os sujeitos foram os responsáveis pelos arquivos localizados no Centro de Educação, Comunicação e Artes.

No roteiro de entrevista, buscou-se identificar os principais documentos gerados, o controle dessa produção, os documentos recebidos de outras unidades/organizações, as datas limites de conservação do documento, os volumes existentes, os critérios de arquivamento, as condições físicas de armazenamento e os critérios de transferência e de descarte. Quanto à situação de consulta desses arquivos, buscou-se levantar os usuários reais e potenciais, bem como a existência de critérios de controle e de empréstimo dos documentos.

\section{TEORIA E PRÁTICA DA GESTÃO DOCUMENTAL E INFORMACIONAL: UM TRECHO PERCORRIDO}

Analisando o problema da gestão da informação no âmbito das instituições públicas, a situação é bastante alarmante e tem sido encaminhada com seriedade pelas instituições arquivísticas brasileiras. $\mathrm{O}$ acúmulo de documentos sem tratamento adequado, a dificuldade de manutenção dos arquivos de processos administrativos, judiciais e 
técnicos, a falta ou inadequação de espaço para a guarda de documentos e a falta de pessoal especializado para organizar os "papéis gerados" apressam as soluções e despertam cada vez mais o interesse dos dirigentes.

As normas estabelecidas pelo Conselho Nacional de Arquivos (Conarq) no tocante aos procedimentos para a gestão de documentos (Resolução nộ, de 18 de outubro de 1995), transferência e recolhimento (Resolução $\mathrm{n}^{\mathrm{O}}$ 2, de 18 de outubro de 1995) e eliminação (Resolução no 5, de 20 de maio de 1997) buscam orientar as instituições arquivísticas brasileiras regulamentando prazos para guarda de documentos da administração pública e apontando diretrizes para a criação de comissões técnicas de avaliação.

É possível observar, no quadro 1, uma "cultura” arquivística inadequada na UEL, que se evidencia no uso do termo "arquivo morto" para designar certos depósitos, ou então, pela escassez absoluta de instrumentos de acesso à documentação; pela eliminação indiscriminada; pela "preservação" da totalidade da documentação, sem nenhum critério de seleção quanto à natureza ou valor de cada documento, resultando no mau gerenciamento das informações orgânicas.

Assim, o grande desafio da instituição analisada passa a ser a "gestão total de informação", que englobe o tratamento do documento desde a sua produção até sua destinação final, garantindo sua integridade e acesso para que a informação esteja disponível no momento necessário de sua respectiva utilização.

Conscientes do nível de complexidade e da falta de recursos financeiros nas instituições públicas de ensino superior, há ainda muito a ser feito, principalmente nos níveis político e de infra-estrutura, para produzir os resultados eficazes e eficientes de uma política de gestão documental e informacional para a Universidade Estadual de Londrina.

No entanto, tendo em vista minimizar a situação aqui detectada, sugere-se a implantação de práticas de gestão documental; a organização dos documentos baseada em procedimentos arquivísticos; a implantação de códigos de assunto no Protocolo Geral; a avaliação da documentação acumulada e a destinação final; a adequação do sistema de protocolo aos procedimentos arquivísticos; a centralização da documentação nas fases permanente e intermediária, em salas de arquivo; a higienização dos documentos de valor permanente; o acondicionamento apropriado para os documentos de tamanho especial e a redefinição (conforme a necessidade) do leiaute dos depósitos.

Diante dessas sugestões, a UEL teria as seguintes vantagens: racionalização do trabalho de arquivamento com aumento de produtividade; a recuperação rápida e precisa de documentos e da informação; o impedimento do acréscimo indiscriminado do volume de documentos e recuperação ágil da informação; a otimização de seus

\section{QUADRO 1}

Análise situacional dos arquivos da UEL, em 2003: causas e efeitos

\begin{tabular}{l|l|}
\hline \multicolumn{1}{c|}{ CAUSAS } & \multicolumn{1}{c|}{ EFEITOS } \\
\hline $\begin{array}{l}\text { Ausência de métodos técnico-científicos } \\
\text { na organização dos processos }\end{array}$ & Dificuldade de busca e perda da informação \\
\hline $\begin{array}{l}\text { Ausência de plano de classificação dos } \\
\text { documentos para a guarda dos processos }\end{array}$ & $\begin{array}{l}\text { Acúmulo indiscriminado de documentos sem nenhum valor } \\
\text { administrativo, técnico-científico, legal ou histórico }\end{array}$ \\
\hline $\begin{array}{l}\text { Deficiência de controle físico de processos } \\
\text { Deficiência das atividades de busca }\end{array}$ & $\begin{array}{l}\text { Comprometimento na apresentação e no ambiente } \\
\text { de trabalho, o que gera perda de produtividade }\end{array}$ \\
\hline Deficiência de controle de empréstimo de processos & Dificuldade no controle da guarda de processos \\
\hline Documentos reunidos sem acondicionamento definitivo & Ameaça da integridade da informação \\
\hline Falta de padronização nas dimensões da estanteria & Dificuldade de circulação (manuseio) no interior dos "depósitos" \\
\hline Utilização de caixas e invólucros de baixa qualidade & $\begin{array}{l}\text { Dificuldade na manutenção das condições de } \\
\text { limpeza e preservação dos documentos }\end{array}$ \\
\hline Acúmulo de documentos nos diversos setores & Comprometimento do ambiente com poluição visual \\
\hline $\begin{array}{l}\text { Mau aproveitamento do espaço com a } \\
\text { utilização dos fichários de aço }\end{array}$ & Perda de espaço físico e dificuldade na busca \\
\hline Acúmulo de "sucata" junto à documentação & Comprometimento das atividades de arquivamento \\
\hline Iniciativas isoladas quanto à gestão de documentos & "Dinheiro público" gasto sem necessidade \\
\hline
\end{tabular}


espaços físicos de trabalho; o controle do trâmite de processos desde sua geração até a sua destinação final; a facilidade de transferência ou eliminação dos documentos; liberação de espaço físico; a preservação e conservação dos documentos e o preparo da documentação para a guarda definitiva ou para a transferência.

Por decorrência, uma das práticas "comuns" do Curso de Arquivologia da UEL é o incentivo à pesquisa na área, o que acarreta desenvolvimento de métodos apropriados à realidade dos arquivos da UEL e da região de Londrina.

\section{CONSIDERAÇÕES FINAIS}

Muitas são as barreiras a serem ultrapassadas quando se fala em uma política de gestão documental/informacional, a começar pela cultura organizacional que resiste a mudanças. A proposta de implantação dessa política implica criação e alterações na elaboração de documentos, com possibilidade de revisão de alguns fluxos informacionais, além de investimentos em qualificação de pessoal, em estrutura física apropriada.

Tendo em vista o longo caminho a ser percorrido, faz-se necessário o reconhecimento da importância da gestão documental/informacional pelo comprometimento da administração e dos produtores dos documentos, para que se consolide o sistema de arquivo em estudo.

O desenvolvimento de um estudo desta natureza traz experiências importantes para a equipe constituída por alunos e professores do Departamento de Ciência da Informação. Busca-se o suporte da literatura especializada, são feitas reflexões a respeito da aplicabilidade dos conhecimentos obtidos em uma realidade concreta, ou seja, o espaço universitário assume o papel de um grande e importante laboratório de ensino.

Essa visão, propiciada pelo caráter multidisciplinar do Curso de Arquivologia da UEL, merece apontar que o gerenciamento desse curso compete aos Departamentos de Ciência da Informação e de História, em uma experiência única, que se configura na interpenetração de diferentes áreas do conhecimento, a saber, ciências sociais aplicadas e ciências humanas.

Ganha com isso o ensino de arquivologia, que se renova mediante a reflexão e a articulação entre teoria e prática; ganha a universidade, ao permitir ser introduzido no seu contexto um gerenciamento documental/informacional mais eficiente; ganham os discentes, pela amplitude de sua capacidade crítica e criativa decorrente da integração dos conhecimentos das diferentes áreas; enfim, ganham todos os atores sociais envolvidos nessa prática investigativa.
Artigo recebido em 12-09-2004 e aceito para publicação em 29-03-2005.

\section{REFERÊNCIAS}

ARQUIVO NACIONAL (Brasil). Resoluções do Conarq. Disponível em: <www.arquivonacional.gov.br/conarq>. Acesso em: 04 out. 2004.

BELLOTTO, Heloísa Liberalli. Arquivos permanentes: tratamento documental. São Paulo: T. A. Queiróz, 1991. 198 p.

BÍBLIA sagrada: antigo e novo testamento. Rio de Janeiro : Vida, 1998.

BRASIL. Lei n 8. 159, de 8 de janeiro de 1991. Diário Oficial [ da] República Federativa do Brasil, Brasília, DF, 9 jan.1999. Seção 1, p. 455.

CAMARGO, Ana M. de Almeida ; BEllotTO, Heloísa L. (Coord.). Dicionário de terminologia arquivística. São Paulo : Associação dos Arquivistas Brasileiros, 1996.

CÔRTES, Maria Regina Persechini Armond. Arquivo público e informação: acesso à informação nos arquivos públicos estaduais do Brasil. Belo Horizonte : Escola de Biblioteconomia da UFMG, 1996.

COUTURE, Carol. Le concept de document d'archives à l'aube du troisième millénaire. Archives, v. 27, n. 4, p. 3-18, 1996.

CRUZ MUNDET, José Ramón. Manual de archivística. 3. ed. Madrid : Fundación Germán Sánches Ruipérez, 1994.

DAVENPORT, Thomas H. Ecologia da informação: porque só a tecnologia não basta para o sucesso na era da informação. Tradução de Bernadette Siqueira Abrão. São Paulo : Futura, 2000. 320 p.

FONSECA, Maria Odila. Informação, arquivos e instituições arquivísticas. Arquivo e Administração, Rio de Janeiro, v. 1, n. 1, p. 33-44, jan./jun. 1998.

FURTADO, João Salvador. Informação e organização. Ciência da Informação, Brasília, v. 11, n. 1, p. 27-33, 1982.

HEREDIA HERRERA, Antônia. Archivística general: teoría y práctica. Sevilla : Disputacíon de Sevilla, 1993. 512 p.

JARDIM, José Maria ; FONSECA, Maria Odila (Org.). A formação do arquivista no Brasil. Niterói, RJ : EdUFF, 1999.

LOPES, Luís Carlos. A gestão da informação: as organizações, os arquivos e a informática aplicada. Rio de Janeiro : Arquivo Público do Estado do Rio de Janeiro, 1997.

A nova arquivística na modernização administrativa. Rio de Janeiro: [s. n.], 2000. 369 p.

LUSTOSA, Jeová Gomes. O comportamento informacional de pesquisadores e gerentes. In: TARGINO, M. G.; CASTRO, M. M .R. N. Desafiando os domínios da informação. Teresina, PI : EDUFPI, 2002.

SOCIEDADE DA INFORMAÇÃO. Grupo de Trabalho: conteúdos e identidade sociais. [S. l.: s. n.], 2000. Documento de trabalho.

ROUSSEAU, Jean-Yves ; COUTURE, Carol. Os fundamentos da disciplina arquivística. Lisboa : Publicações Dom Quixote, 1998.

ROMERO TALlAFIGO, Manuel. Archivística y archivos : soportes, edificio y organización, Carmona : SeC, 1994. 